\title{
The correlation between TNF- $\alpha-308$ gene polymorphism and susceptibility to cervical cancer
}

\author{
LIPING LI, JIE LIU, CHUNJING LIU and XIANGHUI LU \\ Department of Gynaecology and Obstetrics, The Third Affiliated Hospital of Qiqihar \\ Medical University, Qiqihar, Heilongjiang 161000, P.R. China \\ Received October 9, 2017; Accepted February 14, 2018
}

DOI: $10.3892 / \mathrm{ol} .2018 .8246$

\begin{abstract}
Tumor necrosis factor- $\alpha$ (TNF- $\alpha)$ is closely related to the occurrence of human cancers. Cervical cancer seriously affects female health. Therefore, our study aimed to investigate the correlation between the polymorphism of TNF- $\alpha-308$ gene and susceptibility to cervical cancer. Whole blood was collected from 142 patients with cervical cancer and 150 healthy controls. PCR-RFLP was used to detect the polymorphism of TNF- $\alpha-308$ and the correlation between polymorphism of TNF- $\alpha-308$ and the susceptibility to cervical cancer was analyzed. The three genotypes of TNF- $\alpha-308$ were GG, GA and AA, and the distributions of genotypes of TNF- $\alpha-308$ were consistent with Hardy-Weinberg equilibrium in both cervical cancer group and control group. There were no significant differences in genotype and allele frequency between cervical cancer group and healthy control group ( $\mathrm{P}>0.05)$. A/A genotype increased the risk of cervical cancer by 1.46 times with 95\% confidence interval of 0.32-6.67. Different genotypes were not associated with tumor type $(\mathrm{P}>0.05)$. Different genotypes are correlated with cervical cancer TNM stages, tumor differentiation and lymph node metastasis. Proportion of GA+AA genotype in TNM stage III+IV group, low differentiation group and lymph node metastasis group were 28.1, 29.0 and 29.8\%, respectively, which were significantly higher than those in stage I+II group, moderate/high differentiation group and non-lymph node metastasis group $(\mathrm{P}<0.05)$. The results suggested that TNF- $\alpha-308$ gene polymorphism is associated with the degree of malignancy of cervical cancer. Female patients with A allele have higher malignant degree of cervical cancer.
\end{abstract}

Correspondence to: Dr Xianghui Lu, Department of Gynaecology and Obstetrics, The Third Affiliated Hospital of Qiqihar Medical University, 27 Taishun Street, Qiqihar, Heilongjiang 161000, P.R. China E-mail: 16x6nu@163.com

Key words: tumor necrosis factor- $\alpha$, gene polymorphism; cervical cancer

\section{Introduction}

Cervical cancer is one of the most common malignancies in the world, and it affects 500,000 new cases and cause 270,000 deaths each year, which is ranked second in female malignant tumors (1). The effective cervical screening program in developed countries has led to a significant decline in morbidity and mortality of this disease, but in developing countries, morbidity and mortality of cervical cancer are still significantly higher than those in developed countries. In China, cervical cancer affects more than 100,000 new cases each year, which account for $\sim 1 / 3$ of the new cases in the world (2). Human papillomavirus (HPV) infection is a common cause of cervical cancer, in addition, genetic variation is also an important factor leading to the occurrence of cervical cancer (3).

Tumor necrosis factor (TNF) is a kind of proinflammatory cytokine with a variety of biological activities. TNF includes TNF- $\alpha$ and TNF- $\beta$ two types. TNF- $\alpha$ is mainly produced by monocytes/macrophages, and plays an important role in human immune response. TNF- $\alpha$ can play roles as both oncogene and tumor suppressor (4). Under physiological conditions, TNF- $\alpha$ has functions of antitumor, antivirus and immunity enhancement. TNF- $\alpha$ is highly expressed in a variety of tumors and can regulate tumor cell proliferation, invasion and metastasis by regulating tumor angiogenesis (5). TNF- $\alpha$ promoter region gene polymorphism can affect the transcriptional activity of TNF- $\alpha$ in various tumors, and common polymorphic loci include TNF- $\alpha-308$ and -238 locus (6). Gene polymorphism at the TNF- $\alpha-308$ locus in the promoter region of TNF- $\alpha$ gene, which is closely related to the occurrence, development and prognosis of many malignant tumors, has attracted more and more attentions. $\mathrm{G}>\mathrm{A}$ can increase the expression of TNF- $\alpha$. TNF- $\alpha-308$ has three genotypes GG, GA and AA. GG is the most common genotype, and AA is relatively rare. GA+AA genotype can promote the non-specific expression of $\mathrm{TNF}-\alpha$ in various types of tumor to affects its antitumor effect, individual's susceptibility to cancer and the prognosis of patients (7). TNF- $\alpha$ also has diverse functions in cervical cancer. Studies have shown that TNF- $\alpha$ can inhibit transcription of E6/E7 in keratinocytes infected with HPV16. TNF- $\alpha$ can also inhibit HPV18 oncogene transcription $(8,9)$. TNF- $\alpha$ is closely related to the occurrence of cervical cancer, and can increase the risk 
of cervical cancer (10). TNF- $\alpha-308$ locus gene polymorphism is formed by the replacement of guanine (G) by adenine (A). TNF- $\alpha$ can significantly stimulate the immortalized proliferation of HPV cervical cells, and studies have shown that TNF- $\alpha$ gene polymorphism is closely correlated with cervical cancer susceptibility (11). In this study, PCR-RFLP was used to detect TNF- $\alpha-308$ gene polymorphism and between TNF- $\alpha-308$ gene polymorphism and cervical cancer susceptibility was analyzed.

\section{Materials and methods}

General information. A total of 142 patients with cervical cancer were selected from January 2012 to December 2016 in the Third Affiliated Hospital of Qiqihar Medical University (Qiqihar, China). All patients were diagnosed with cervical cancer by the pathological examinations. All patients have complete clinical data, and the average age was $52 \pm 15$ years. At the same time, 150 healthy volunteers ( $52 \pm 15$ years) without blood relationship with those patients were also selected to serve as control group. All participants were females. This study was approved by the Ethics Committee of the Third Affiliated Hospital of Qiqihar Medical University (Qiqihar, China) and all participants signed informed consent.

Genomic DNA extraction. Whole blood was extracted from each participant with EDTA as anticoagulant. Genomic DNA was extracted using the whole blood genomic DNA rapid extraction kit (DP1103; Bioteke, Beijing, China) according to the instructions of the kit. DNA samples were stored at $-20^{\circ} \mathrm{C}$.

PCR amplification. Polymorphism of TNF- $\alpha-308$ locus was analyzed by restriction fragment length polymorphism polymerase chain reaction (PCR-RFLP). TNF- $\alpha-308$ specific primers were: 5'-TCCCCAAAAGAAATGGAGGCAATA-3' (sense) and reverse primer, 5'-GG TTTTGAGGGCCATGAG ACGTCTGCT GGCTGGGTG-3' (antisense). Primers and PCR kits were provided by Beijing SBS Genetech Co., Ltd. (Beijing, China) PCR reaction conditions: $95^{\circ} \mathrm{C}$ for $12 \mathrm{~min}$, followed by 35 cycles of $95^{\circ} \mathrm{C}$ for $30 \mathrm{sec}, 60^{\circ} \mathrm{C}$ for $30 \mathrm{sec}$ and $72^{\circ} \mathrm{C}$ for $60 \mathrm{sec}$, and then $72^{\circ} \mathrm{C}$ for $5 \mathrm{~min}$.

TNF- $\alpha-308$ gene polymorphism detection. TNF- $\alpha-308$ amplification product was digested with $N c o$ I restriction enzyme (Thermo Fisher Scientific, Inc., Waltham, MA, USA) overnight at $37^{\circ} \mathrm{C}$, followed by $3 \%$ agarose gel electrophoresis. Results were observed under UV lights. Purple GG wild-type homozygous genotype provide 326 and 36 bp fragments, AG heterozygous genotype would provide 362,326 and $36 \mathrm{bp}$ fragments, and AA mutant homozygous genotype would only provide a $362 \mathrm{bp}$ fragment.

Statistical analysis. Statistical analysis was performed using SPSS 17.0 software (SPSS, Inc., Chincago, IL, USA). Hardy-Weinberg equilibrium and comparisons between groups were analyzed by $\chi^{2}$ test and Fisher's exact test. $P<0.05$ was considered to indicate a statistically significant difference. Odds ratio (OR) and 95\% confidence interval (CI) were calculated.
Table I. Clinical and pathological data of 142 cases of cervical cancer.

\begin{tabular}{lcc}
\hline Clinical and pathological data & Cases (n) & Percentage (\%) \\
\hline Age (years) & & \\
$\quad<60$ & 84 & 59.2 \\
$\geq 60$ & 58 & 40.8 \\
Histological classification & & \\
$\quad$ Squamous cell carcinoma & 128 & 90.1 \\
Adenocarcinoma & 9 & 6.3 \\
Other types & 5 & 3.5 \\
TNM stages & & \\
I+II & 78 & 54.9 \\
III+IV & 64 & 45.1 \\
Differentiation & & \\
Low & 69 & 48.6 \\
Moderate/high & 73 & 51.4 \\
Lymph node metastasis & & \\
Yes & 57 & 40.1 \\
No & 85 & 59.9 \\
\hline
\end{tabular}

\section{Results}

Clinical and pathological data. There were 142 cases of cervical cancer with an average age of $52 \pm 15$ years, and 150 cases of healthy people with an average age of $50 \pm 13$ years. No significant differences in age were found between two groups ( $\mathrm{t}=0.68$, $\mathrm{P}=0.25$ ). Among the 142 cases of cervical cancer, 84 cases were $<60$ years old, and 58 cases were $\geq 60$ years old. Histological classification: 128 cases of squamous cell carcinoma, 9 cases of adenocarcinoma, and 5 cases of other types. TNM stages: 78 cases of stage I+II, 64 cases of stage III+IV, 69 cases of low differentiation, 73 cases of moderate and high differentiation, 57 cases of lymph node metastasis and 85 cases of non-lymph node metastasis (Table I).

Comparison of TNF- $\alpha-308$ gene polymorphism and allele frequency between cervical cancer group and control group. TNF- $\alpha-308$ gene polymorphism was found in both cervical cancer group and control group. Three genotypes of TNF- $\alpha-308$ were GG, GA and AA. In cervical cancer group, GG was found in 114 cases (80.3\%), GA was found in 24 cases (16.9\%), and AA was found in 4 cases (2.8\%). In control group, GG was found in 125 cases (83.3\%), GA was found in 22 cases (14.7\%), and AA was found in 3 cases $(2.0 \%)$. The frequencies of $\mathrm{G}$ and $\mathrm{A}$ alleles in cervical cancer patients were 88.7 and $11.3 \%$, respectively, and the frequencies in control group were 0.7 and $9.3 \%$, respectively. All those data met Hardy-Weinberg equilibrium law (Table II). A $\chi^{2}$ test showed no significant differences in genotype and allele frequency between cervical cancer group and control group $(\mathrm{P}>0.05)$.

Comparison of risk between genotypes. With G/G type as reference, G/A type increased the risk of cervical cancer by 1.20 times with $95 \% \mathrm{CI}$ of $0.64-2.25$, and $\mathrm{A} / \mathrm{A}$ type increased 
Table II. Comparison of TNF- $\alpha-308$ gene polymorphism and allele frequency between cervical cancer and control group.

\begin{tabular}{lccr}
\hline $\begin{array}{l}\text { Gene polymorphism } \\
\text { and allele frequency }\end{array}$ & $\begin{array}{c}\text { Cervical cancer group } \\
(\mathrm{n}=142)(\%)\end{array}$ & $\begin{array}{c}\text { Control group } \\
(\mathrm{n}=150)(\%)\end{array}$ & $\chi^{2}$ \\
\hline Genotype & $114(80.3)$ & $125(83.3)$ & 0.772 \\
GG & $24(16.9)$ & $22(14.7)$ & $3(2.0)$ \\
GA & $4(2.8)$ & $272(90.7)$ & 0.592 \\
AA & & $28(9.3)$ & 0.496 \\
Allele frequency & $252(88.7)$ & & \\
G & $32(11.3)$ & & \\
A & & & \\
\hline
\end{tabular}

TNF- $\alpha$, tumor necrosis factor- $\alpha$.

Table III. Comparison of risk between genotypes.

\begin{tabular}{|c|c|c|c|c|c|c|}
\hline $\begin{array}{l}\text { Gene polymorphism } \\
\text { and allele frequency }\end{array}$ & $\begin{array}{l}\text { Cervical cancer } \\
\text { group (no) }\end{array}$ & $\begin{array}{c}\text { Control } \\
\text { group (no) }\end{array}$ & $\chi^{2}$ & P-value & OR & CI \\
\hline \multicolumn{7}{|l|}{ Genotype } \\
\hline GG & 114 & 125 & & & 1 & \\
\hline GA & 24 & 22 & 0.31 & 0.58 & 1.20 & $(0.64-2.25)$ \\
\hline AA & 4 & 3 & 0.24 & 0.66 & 1.46 & $(0.32-6.67)$ \\
\hline \multicolumn{7}{|l|}{ Allele frequency } \\
\hline G & 252 & 272 & & & 1 & \\
\hline A & 32 & 28 & 0.60 & 0.50 & 1.23 & $(0.77-2.11)$ \\
\hline
\end{tabular}

OR, odds ratio; CI, confidence interval.

Table IV. Correlation between TNF- $\alpha-308$ gene polymorphism and clinicopathological data of cervical cancer patients.

\begin{tabular}{|c|c|c|c|c|c|}
\hline \multirow[b]{2}{*}{ Clinical and pathological data } & \multirow[b]{2}{*}{ Cases (no) } & \multicolumn{2}{|c|}{ TNF- $\alpha-308$ genotype } & \multirow[b]{2}{*}{$\chi^{2}$} & \multirow[b]{2}{*}{ P-value } \\
\hline & & GG & $\mathrm{GA}+\mathrm{AA}$ & & \\
\hline \multicolumn{6}{|l|}{ Age (years) } \\
\hline$<60$ & 84 & 65 & 19 & & \\
\hline$\geq 60$ & 58 & 49 & 9 & 1.09 & 0.39 \\
\hline \multicolumn{6}{|l|}{ Histological classification } \\
\hline Squamous cell carcinoma & 128 & 103 & 25 & & \\
\hline Adenocarcinoma & 9 & 7 & 2 & & \\
\hline Other types & 5 & 4 & 1 & 0.04 & 0.98 \\
\hline \multicolumn{6}{|l|}{ TNM stages } \\
\hline $\mathrm{I}+\mathrm{II}$ & 78 & 68 & 10 & & \\
\hline III+IV & 64 & 46 & 18 & 5.20 & 0.03 \\
\hline \multicolumn{6}{|l|}{ Differentiation } \\
\hline Low & 69 & 49 & 20 & & \\
\hline Moderate/high & 73 & 65 & 8 & 7.28 & 0.01 \\
\hline \multicolumn{6}{|l|}{ Lymph node metastasis } \\
\hline Yes & 57 & 40 & 17 & & \\
\hline No & 85 & 72 & 11 & 5.80 & 0.02 \\
\hline
\end{tabular}

TNF- $\alpha$, tumor necrosis factor- $\alpha$. 
the risk of cervical cancer by 1.46 times with $95 \%$ CI of 0.32-6.67. But no significant differences were found among them $(\mathrm{P}>0.05)$. The $\mathrm{OR}$ of A allele carriers to $\mathrm{G}$ allele carriers was 1.23 with $95 \%$ CI of 0.77-2.11. Comparison of genotype and allele frequencies showed no significant differences (P>0.05) (Table III).

Correlation between TNF- $\alpha-308$ gene polymorphism and clinicopathological data of cervical cancer patients. Genotypes of TNF- $\alpha-308$ were divided into GG and GA+AA groups. Correlations between different genotypes, histological classification, clinical stage, differentiation and lymph node metastasis were analyzed. Different genotypes were not significantly associated with histological classification $(\mathrm{P}>0.05)$. Different genotypes were associated with TNM stages, tumor differentiation and lymph node metastasis in patients with cervical cancer. GA+AA genotype accounted for $12.8 \%$ of patients in TNM stage I+II, and $28.1 \%$ in stage III+IV. The percentage of GA+AA genotype is significantly higher in stage III+IV than in stage $\mathrm{I}+\mathrm{II}(\mathrm{P}<0.05)$. GA+AA genotype accounted for $29.0 \%$ in low differentiation group and $11.0 \%$ in moderate and high differentiation group. The percentage of GA+AA genotype is significantly higher in low differentiation group than in moderate and high differentiation group $(\mathrm{P}<0.05)$. GA+AA genotype accounted for $29.8 \%$ in lymph node metastasis group and $12.9 \%$ in non-lymph node metastasis group. The percentage of GA+AA genotype is significantly higher in lymph node metastasis group than in non-lymph node metastasis group $(\mathrm{P}<0.05)$ (Table IV).

\section{Discussion}

As a cytokine with strong antitumor effect, TNF- $\alpha$ has various functions, including antitumor, antivirus and immune enhancement. However, it has been found that TNF- $\alpha$ is also closely related to the development of tumor. TNF- $\alpha$ secreted by tumor tissue can promote the growth of tumor cells, stimulate angiogenesis and accelerate the occurrence and progression of cancer (12). TNF- $\alpha$ is closely correlated with breast cancer, rectal cancer, gastric cancer and other types of cancers $(13,14)$.

This study was to investigate the relationship between TNF- $\alpha-308$ gene polymorphism and susceptibility to cervical cancer. Similarly results were reported in the paper in which no significant difference in TNF- $\alpha-308$ genotype distribution was found between cervical cancer patients and control people (15). In addition to cervical cancer, A allele is closely related to a variety of tumors. Single nucleotide polymorphisms of the TNF promoter region $(-308 \mathrm{G}>\mathrm{A})$ are closely related to the prevalence of gastric cancer in China. The frequency of heterozygous mutation (GA) and secondary allele (A) is significantly higher in gastric cancer patients than in healthy control group $(16,17)$. TNF- $\alpha-308$ allele polymorphism is associated with body mass index (BMI) and distant metastasis of colorectal cancer patients, and A allele can increase the risk of distant metastasis of colorectal cancer (18).

Numerous studies have shown that TNF- $\alpha-308$ genotypes are closely correlated with the susceptibility to cervical cancer. The polymorphism of TNF- $\alpha-308$ gene in Caucasians and Africans is associated with the susceptibility to cervical cancer. The frequency of A allele in cervical cancer patients is higher than that in healthy people. A allele can promote the infiltration of cervical cancer (19-21). However, studies have shown that TNF- $\alpha-308$ genotypes have no effects on the risk of cervical cancer in Asian people (22). Environmental and psychological factors can affect experimental results. The correlation between TNF- $\alpha-308$ gene polymorphism and cervical cancer needs to be further studied (23). In this study, no significant differences in TNF- $\alpha-308$ genotype were found between cervical cancer group and control group, but GA+AA genotype is associated with the degree of malignancy of cervical cancer. A allele can increase the degree of malignancy, so the detection of TNF- $\alpha-308$ gene polymorphism in cervical cancer patients may facilitate the monitoring and prognosis. However, the detection of TNF- $\alpha-308$ gene polymorphism is complicated, which limited the application of this technique. Confounding bias of this study was caused by individual living habits, economic conditions and psychological factors. Therefore, our future studies will include more patients from different regions to further confirm the conclusions in this study. We will also optimize the studies on TNF- $\alpha$ polymorphism sites to comprehensively investigate the occurrence and development of this disease.

\section{Acknowledgements}

Not applicable.

\section{Funding}

No funding was received.

\section{Availability of data and materials}

The datasets used and/or analyzed during the present study are available from the corresponding author on reasonable request.

\section{Authors' contributions}

LL wrote the manuscript and helped with the genomic DNA extraction. JL performed PCR amplification. CL and XL contributed significantly to gene polymorphism detection. All authors read and approved the final manuscript.

\section{Ethics approval and consent to participate}

This study was approved by the Ethics Committee of the Third Affiliated Hospital of Qiqihar Medical University (Qiqihar, China) and all participants signed informed consent.

\section{Consent for publication}

Not applicable.

\section{Competing interests}

The authors declare that they have no competing interests.

\section{References}

1. Torre LA, Bray F, Siegel RL, Ferlay J, Lortet-Tieulent J and Jemal A: Global cancer statistics, 2012. CA Cancer J Clin 65: 87-108, 2015 
2. Lo KW, Wong YF, Chan MK, Li JC, Poon JS, Wang VW, ZhuSN, Zhang TM, He ZG, Wu QL, et al: Prevalence of humanpapillomavirus in cervical cancer: A multicenter study in China. Int J Cancer 100: 327-331, 2002.

3. Cornet I, Gheit T, Iannacone MR, Vignat J, Sylla BS, Del MistroA, Franceschi S, Tommasino M and Clifford GM: HPV16 genetic variation and the development ofcervical cancer worldwide. Br J Cancer 108: 240-244, 2013.

4. Balkwill F: Tumor necrosis factor or tumor promoting factor? Cytokine Growth Factor Rev 13: 135-141, 2002.

5. Ding B, Fu S, Wang M, Yue C, Wang W, Zhou D, Zhang Z and Han S: Tumor necrosis factor $\alpha-308 \mathrm{G}>\mathrm{A}$ polymorphisms and cervical cancer risk: A meta-analysis. Int J Gynecol Cancer 22: 213-219, 2012

6. Suganuma M, Kurusu M, Suzuki K, Nishizono A, Murakami K, Fujioka $\mathrm{T}$ and Fujiki $\mathrm{H}$ : New tumor necrosis factor- $\alpha$-inducing protein released from Helicobacter pylori for gastric cancer progression. J Cancer Res Clin Oncol 131: 305-313, 2005.

7. Kroeger KM, Carville KS and Abraham LJ: The -308 tumor necrosis factor- $\alpha$ promoter polymorphism effects transcription. Mol Immunol 34: 391-399, 1997.

8. Soto U, Das BC, Lengert M, Finzer P, zur Hausen H and Rösl F: Conversion of HPV 18 positive non-tumorigenic HeLa-fibroblast hybrids to invasive growth involves loss of TNF-alpha mediated repression of viral transcription and modification of the AP-1 transcription complex. Oncogene 18: 3187-3198, 1999.

9. Kyo S, Inoue M, Hayasaka N, Inoue T, Yutsudo M, Tanizawa O and Hakura A: Regulation of early gene expression of human papillomavirus type 16 by inflammatory cytokines. Virology 200 : 130-139, 1994.

10. Roszak A, Misztal M, Sowińska A and Jagodziński PP: TNF- $\alpha-308 \mathrm{G} / \mathrm{A}$ as a risk marker of cervical cancer progression in the Polish population. Mol Diagn Ther 19: 53-57, 2015.

11. Woodworth CD, McMullin E, Iglesias M and Plowman GD Interleukin 1 alpha and tumor necrosis factor alpha stimulate autocrine amphiregulin expression and proliferation of human papillomavirus-immortalized and carcinoma-derived cervical epithelial cells. Proc Natl Acad Sci USA 92: 2840-2844, 1995.

12. Mocellin S and Nitti D: TNF and cancer: The two sides of the coin. Front Biosci 13: 2774-2783, 2008.

13. Zhang Q, Zhao GS, Yuan XL, Li XH, Yang Z, Cui YF, Guan QL, Sun XY, Shen W, Xu TA, et al: Tumor necrosis factor alpha238G/A polymorphism and risk of breast cancer: An update by meta-analysis. Medicine (Baltimore) 96: e7442, 2017.

14. Banday MZ, Balkhi HM, Hamid Z, Sameer AS, Chowdri NA and Haq E: Tumor necrosis factor- $\alpha$ (TNF- $\alpha)-308 \mathrm{G} / \mathrm{A}$ promoter polymorphism in colorectal cancerin ethnic Kashmiri populationA case control study in a detailed perspective. Meta Gene 9: 128-136, 2016
15. Wang Q, Zhang C, Walayat S, Chen HW and Wang Y: Association between cytokine gene polymorphisms and cervical cancer in a Chinese population. Eur J Obstet Gynecol Reprod Biol 158: 330-333, 2011.

16. Du LC and Gao R: Role of TNF- $\alpha-308 \mathrm{G} / \mathrm{A}$ gene polymorphism in gastric cancer risk: A case control study and meta-analysis. Turk J Gastroenterol 28: 272-282, 2017.

17. de Oliveira JG, Rossi AF, Nizato DM, Cadamuro AC, Jorge YC, Valsechi MC, Venâncio LP, Rahal P, Pavarino ÉC, Goloni-Bertollo EM, et al: Influence of functional polymorphisms in TNF- $\alpha$, IL-8, and IL-10 cytokine genes on mRNA expression levels and risk of gastric cancer. Tumour Biol 36: 9159-9170, 2015

18. Li Z, Li SA, Sun Y, Liu Y, Li WL, Yang L, Duan Y, Li J, Guo H, Zou TN, et al: TNF- $\alpha-308$ A allele is associated with an increased risk of distant metastasis in rectal cancer patients from Southwestern China. PLoS One 12: e0178218, 2017.

19. Sousa H, Oliveira S, Santos AM, Catarino R, Moutinho J and Medeiros R: Tumour necrosis factor alpha $308 \mathrm{G} / \mathrm{A}$ is a risk marker for the progression from high-grade lesions to invasive cervical cancer. Tumour Biol 35: 2561-2564, 2014

20. Barbisan G, Pérez LO, Contreras A and Golijow CD: TNF- $\alpha$ and IL-10 promoter polymorphisms, HPV infection, and cervical cancer risk. Tumour Biol 33: 1549-1556, 2012.

21. Govan VA, Constant D, Hoffman M and Williamson AL: The allelic distribution of -308 tumor necrosis factor-alpha gene polymorphism in South African women with cervical cancer and control women. BMC Cancer 6: 24, 2006.

22. Wang N, Yin D, Zhang S, Wei H, Wang S, Zhang Y, Lu Y, Dai S, $\mathrm{Li}$ W, Zhang Q, et al: TNF-alpha rs1800629 polymorphism is not associated with HPV infection or cervical cancer in the Chinese population. PLoS One 7: e45246, 2012.

23. Kohaar I, Thakur N, Salhan S, Batra S, Singh V, Sharma A, Sodhani P, Das BC, Sarkar DP and Bharadwaj M: TNFalpha-308G/A polymorphism as a risk factor for HPV associated cervical cancer in Indian population. Cell Oncol 29: 249-256, 2007.

This work is licensed under a Creative Commons Attribution-NonCommercial-NoDerivatives 4.0 International (CC BY-NC-ND 4.0) License. 